ISSN : 2087-2461

PENANGGUNG JAWAB Dekan FIKOM

Evie Sofiati MI, M.I.Kom

Sekretaris Dekan

Dian Marhaeni K, M.Si

Ketua Penyunting

Made Dwi Adnjani, M.Si

Sekretaris

Mubarok, M.Si

Bendahara

Parwati, SH

Dewan Penyunting

Trimanah, M.Si

Edi Ismoyo, M.Si

Suharyoso, S.Sos

Seksi Usaha

Endang Winarsih, S.Sos

Sirkulasi dan Distribusi

Aldino Leoniv, ST

Alamat Redaksi

Fakultas Ilmu Komunikasi

Universitas Islam

Sultan Agung Semarang

J1. Raya Kaligawe Km. 4

Po. Box 1054/SM

Semarang 50112

Telp. (024) 6583584

ext. $448 / 449$

Fax. (024) 6582455

email : jurnalfikom@yahoo.com
Pengaruh Perubahan Nama Terhadap Citra Pada Telkom

University

Felesia Ekafaya Kirianawati, Roro Retno Wulan,

Kharisma Nasionalita

felesiaekafay@gmail.com

Komunikasi Lintas Budaya Etnis India, Etnis China serta

Pribumi di kampung Lubuk Pakam

Meilani Dhamayanti

mdhamayanti73@gmail.com

Analisis Komunikasi Pemasaran Melalui Strategi Brand Activation Pond's Untuk Meraih Top Brand Award 2013 Rustono Farady Marta ${ }^{1}$, Pricillia ${ }^{2}$, Maria Fransisca Kosasih ${ }^{3}$, Maria Christina Evelyn Iskandar ${ }^{4}$

rustonofarady@gmail.com ${ }^{1}$, icil_22@hotmail.com ${ }^{2}$, s43_s43@yahoo.com ${ }^{3}$,

mariachristinaevelyne@gmail.com ${ }^{4}$

Analisis Isi Visual Iklan Dan Strategi Kreatif Kategori Print Ad Pemenang Gold, Silver, dan Bronze Citra Pariwara 2015

Dina Nur Handayani ${ }^{1}$ (dinurhdyn@gmail.com)

Ratih Hasanah Sudrajat ${ }^{2}$ (kumaharatih@gmail.com ${ }^{2)}$

Ayub Ilfandy Imran ${ }^{3}$ (a_ilfandy@yahoo.com ${ }^{3}$ )

Refleksi Citra Indonesia Sebagai Dampak Politik Migrasi TKI

ke Malaysia

Mutia Rahmi Pratiwi (mutiarahmipratiwi@gmail.com)

Amida Yusriana (amidayusriana88@gmail.com)

$46-59$

Karakteristik Press Release Praktisi Public Relations Hotel di Yogyakarta

Margaretha Sonya, Meylani Yo, Nobertus Ribut Santoso

margaretha_sonyalee@yahoo.com

$60-70$

Isu LGBT dalam Bingkai Media Online

Muhammad Ghifari Putra ${ }^{1}{ }^{1}$ ghifarigp@gmail.com)

Kharisma Nasionalita ${ }^{2}$

${ }^{2}$ nasionalita.kharisma@gmail.com

$71-87$

Telepon Selular dan Ruang Publik : Representasi Identitas Siswantini

yjuliman@gmail.com

$88-94$

Kepemilikan dan Bingkai Media (Analisis Framing Pemberitaan Joko Widodo Sebagai Kandidat Calon Presiden pada Koran SINDO)

Nani Kurniasaril (nani.kurniasari@kalbis.ac.id ${ }^{1}$ )

Gilang GustiAji² (gilangaji@unesa.ac.id²)

$96-116$ 


\title{
ANALISIS ISI VISUAL IKLAN DAN STRATEGI KREATIF KATEGORI PRINT AD PEMENANG GOLD, SILVER, DAN BRONZE CITRA PARIWARA 2015
}

\author{
Oleh : \\ Dina Nur Handayani ${ }^{1}$, Ratih Hasanah Sudrajat ${ }^{2}$, Ayub Ilfandy Imran ${ }^{3}$ \\ Prodi S1 Ilmu Komunikasi ${ }^{1}$, Fakultas Komunikasi dan Bisnis ${ }^{2}$, Universitas Telkom ${ }^{3}$ \\ dinurhdyn@gmail.com ${ }^{1}$, kumaharatih@gmail.com ${ }^{2}$, a_ilfandy@yahoo.com ${ }^{3}$
}

\begin{abstract}
Competition in product marketing happens very strict. Not only in product differentiation or pricing strategy determined by the company, the competition also happens in product promotion. One of the tools for product promotion is advertisement. Nowadays, the development of advertisement making is vary across of organization, university student bachelor at advertising or marketing pratical.Such development makes Persatuan Perusahaan Periklanan Indonesia (PPPI/P3I) hold an event of appreciation in advertising industry at Indonesia called Citra Pariwara. Citra Pariwara is held annualy for received appreciation of gold, silver, and, bronze. The purpose of this research is to discover visual content message, visual technique, and creative strategy which is made by the winners print ad category of gold, silver, and bronze of Citra Pariwara 2015. This research used quantitative descriptive method with content analysis technique. The object of analysis are 19 of print ad.The result of the analysis is divided into 6 analysis units from each category. The result indicates that visual content message which is dominant is message delivered by hint/ metaphore technique/ (lateral) with 58\%. Visual techniques that is used in headline is picture and information with $32 \%$. Meanwhile, in layout category used frame layout with 58\%. Then, the category of creative strategy with creative strategy approachment used USP (Unique Selling Proposition) with 53\%. Point of interest approachment which is used is combination approach with $37 \%$, on the other hand format and message excecution style used dramatize approach with $58 \%$.
\end{abstract}

Keywords: Content Analysis Quantitative Descriptive, Visual Advertising, Creative Strategy

\begin{abstract}
Abstrak
Persaingan dalam memasarkan produk saat ini tidak hanya dinilai dari diferensiasi produk ataupun strategi harga akan tetapi meliputi aspek untuk mempromosikan produknya. Salah satu sarana untuk mempromosikan suatu produk yaitu, iklan. Perkembangan dalam membuat iklan pun beragam terdiri dari organisasi, mahasiswa jurusan periklanan ataupun praktisi pemasaran. Hal ini membuat Persatuan Perusahaan Periklanan Indonesia (PPPI/P3I) mengadakan acara penghargaan dalam industri periklanan Indonesia yaitu Citra Pariwara. Citra Pariwara sendiri diadakan tiap tahun untuk mendapatkan penghargaan piala, gold, silver, dan bronze. Tujuan penelitian ini adalah untuk mengetahui isi pesan visual, teknik visual, dan strategi kreatif yang dibuat oleh pemenang kategori print ad gold, silver, dan bronze Citra Pariwara 2015. Metode yang digunakan yaitu kuantitatif deskriptif dengan teknik analisis isi. Objek yang dianalisis ada 19 karya iklan cetak. Dari hasil penelitian yang dibagi kedalam 6 unit analisis dari tiap kategori menunjukan bahwa isi pesan visual yang paling dominan adalah pesan tersampaikan dengan kias/ teknik metafora/ (lateral) dengan presentase sebesar 58\%. Teknik visual yang dipakai berdasarkan headline adalah jenis headline yang menggunakan gambar dan keterangan dengan presentase sebesar $32 \%$, dan tata letak/layout menggunakan frame layout dengan presentase


sebesar 58\%. Lalu, dari kategori penggunaan strategi kreatif dengan pendekatan strategi kreatif memakai USP (Unique Selling Proposition) dengan presentase sebesar 53\%, pendekatan daya tarik pesan yang digunakan adalah daya tarik pesan kombinasi dengan presentase sebesar 37\%, sedangkan penggunaan format dan gaya eksekusi pesan menggunakan dramatisasi dengan presentase sebesar 58\%.

\section{Kata kunci: Analisis isi Kuantitatif deskriptif, Visual Iklan, Strategi Kreatif}

\section{Pendahuluan}

Persaingan dalam industri barang dan jasa yang memasarkan produk sebagai landasan ekonomi bagi kelangsungan berjalannya perusahaan terjadi sangat ketat. Persaingan tidak hanya dinilai dari diferensiasi produk ataupun strategi harga yang sudah dirancang oleh perusahaan sendiri akan tetapi meliputi aspek untuk mempromosikan produknya. Salah satu sarana untuk mempromosikan suatu produk yaitu, iklan.

Iklan merupakan bagian penting dan tak terpisahkan dalam kegiatan pemasaran, iklan menjadi suatu hal yang fundamental untuk produk dengan bauran pemasaran berbagai bentuk usaha yang meliputi usaha eceran hingga usaha multinasional. Dalam [6](Morrisan, 2010:1) menyatakan pada sistem ekonomi yang berlandaskan pada pasar, konsumen semakin mengandalkan iklan dan bentuk promosi lainnya untuk mendapatkan informasi yang akan mereka gunakan untuk membuat keputusan apakah akan membeli suatu produk ataukah tidak.

Ralph S. Alexander, (1965) menyatakan bahwa iklan atau advertising dapat didefinisikan sebagai "any paid form of nonpersonal communication about an organization, product, service or idea by an identified sponsor" (setiap bentuk komunikasi nonpersonal mengenai suatu organisasi, produk, servis, atau ide yang dibayar oleh satu sponsor yang diketahui).

Pembuatan iklan sendiri pun biasanya terinspirasi dari bagaimana social trend, pada saat iklan itu dibuat seperti dikutip dari jurnal Content Analysis of Advertisements in Different Cultures. "Ad- vertisements have the potential to greatly impact our lives. They show current trends in social preferences, they reveal cultural values and norms of the target audience and, finally, they can be the mirror of the times people live in" (Iklan mempunyai pengaruh besar yang potensial untuk hidup kita. Iklan menunjukan preferensi trend sosial di jamannya, iklan menampakkan nilai budaya dan norma dalam target pasarnya, akhirnya, iklan bisa menjadi cerminan bagaimana orang hidup pada saat itu).

Kutipan tersebut bisa disimpulkan bahwa iklan dapat menjadi bagian dari hidup kita secara tidak langsung, iklan dapat menunjukan bagaimana dan apa yang menjadi dasar pembuatan iklan itu sendiri terbentuk, faktor lingkungan dan apa yang sedang terjadi dan menjadi trend bisa menjadi tolak ukur bagaimana iklan dikomunikasikan agar menjadi citra produk yang menarik.

Iklan dalam pembuatannya, biasanya suatu instansi melakukan pertimbangan- pertimbangan tujuan danbagaimana pesan akan dikomunikasikan sehingga pesan dari produk dapat disampaikan secara kontekstual dan latent. [6](Morrisan, 2010:134), pemasang iklan atau client adalah pihak paling penting dalam proses periklanan dan promosi. Pemasang iklan adalah pemilik produk (barang dan/ jasa) yang akan dipasarkan dan juga penyedia dana yang akan digunakan untuk iklan dan promosi. Biasanya client dalam hal ini perusahaan mempunyai departemen iklan internal sendiri (in-house agency). Namun demikian, banyak juga perusahaan yang lebih suka menggunakan jasa perusahaan iklan eksternal, yaitu perusahaan luar yang menyediakan pembuatan iklan kepada client. 
Dina Nur Handayani, Ratih Hasanah Sudrajat, Ayub Ilfandy Imran

Perkembangan membuat iklan pun saat ini tidak hanya berpengaruh daripada client banyak juga orang, organisasi, mahasiswa jurusan periklanan ataupun praktisi pemasaran yang mencoba untuk membuat iklan dengan tujuan mengkomunikasikan produk yang dipilih sebagai visualisasi yang kreatif dan pesan yang disampaikan oleh mereka dapat tersampaikan kepada khalayak. Pikiran adalah suatu hal yang abstrak, pikiran dapat berbeda-beda bagi setiap orang. Begitu juga iklan kreatif, iklan kreatif dalam sudut pandangnya mempunyai banyak persepsi yang berbeda tergantung orang menginterpretasikannya.

Hal ini mendorong Persatuan Perusahaan Periklanan Indonesia (PPPI/P3I) mengadakan acara penghargaan dalam industri periklanan Indonesia. Sejak 1989 secara rutin setiap tahun diselenggarakan festival iklan Citra Pariwara. Citra pariwara adalah acara dimana adu kreatifitas industri periklanan untuk mendapatkan penghargaan piala gold, silver, atau bronze.

Citra Pariwara Indonesia pada tahun 2015 ini mengusung tema "stop making sense" tema yang dibuat oleh Citra Pariwara ini mengajak insan kreatif untuk merayakan inner child, silliness, imagination, dan stubbornness. Hal-hal tersebut dirayakan oleh Cita Pariwara 2015 pada tahun ini dan panitia mengajak insan kreatif mengeluarkan sisi-sisi tersebut agar iklan yang nantinya dibuat menjadi iklan yang kreatif, berbeda dan tidak masuk akal akan tetapi tetap bermain dalam aturan yang ada. Kenyataannya Citra Pariwara 2015 mengajak untuk bagaimana insan kreatif dapat membangun citra brand yang kuat, berkomunikasi dengan orang lebih baik dan melakukan hal yang baik untuk lingkungan.

Banyaknya kategori yang dilombakan oleh Citra Pariwara 2015, print ad menjadi objek penelitian dari penulis. penulis memilih kategori print ad karena, print ad menjadi media pertama yang
Analisis Isi Visual Iklan Dan Strategi Kreatif Kategori Print Ad Pemenang Gold, Silver, Dan Bronze Citra Pariwara 2015 dikenal oleh masyarakat sebagai media untuk melakukan kegiatan beriklan sebelum media elektronik (televisi dan radio) dan menjadi suatu hal yang potensial untuk produsen memasarkan produknya. Media cetak biasanya memberikan informasi yang lebih detail tentang produk daripada di media elektronik. Mengutip dari (Morrisan, 2010:279), print ad mempunyai durability yang panjang, print ad dapat didigitalisasi, serta print ad dapat diarsipkan. Dalam kategorisasinya iklan print ad dapat dicetak dalam media BTL (below the line), media below the line meliputi Outdoor/Out of Home (OOH), papan reklame (bilboard), poster, banner, dan spanduk dan POS (points of sales) : leaflet, pamflet, brosur, handbill (selebaran), dan stiker.

Pembuatan suatu iklan tidak lepas dari unsur-unsur pokok yang harus diperhitungkan agar menjadi iklan yang kreatif serta pesan yang akan dimunculkan dapat tersampaikan. Dengan begitu, Penelitian ini menggunakan studi analisis isi dengan metode deskriptif kuantitatif dengan bantuan interpretasi dari ketiga coder dan coding sheet sebagai sumber reliabilitas objek. Iklan pemenang (gold, silver, bronze) Citra Pariwara 2015 kategori print ad sebanyak 19 karya.

Analisis isi pada iklan cetak tersebut dianalisis untuk menjawab pertanyaan sebagai berikut:

1. Bagaimana isi pesan visual yang dibuat oleh pemenang (gold, silver, bronze) Citra Pariwara Indonesia 2015 kategori print ad?

2. Bagaimana teknik visual yang dibuat oleh pemenang (gold, silver, bronze) Citra Pariwara Indonesia 2015 kategori print ad?

3. Bagaimana strategi kreatif yang dibuat oleh pemenang (gold, silver, bronze) Citra Pariwara Indonesia 2015 kategori print ad? 
Dina Nur Handayani, Ratih Hasanah

Sudrajat, Ayub Ilfandy Imran

\section{Dnjalian Pustaka}

\section{Periklanan}

Periklanan adalah komunikasi komersil dan non personal tentang sebuah organisasi dan produkproduknya yang ditransimi-kan ke suatu khalayak target melalui media bersifat massal seperti televisi, radio koran, majalah, direct mail (pengeposan langsung), reklame luar ruang, atau kendaraan umum [4](Lee, M \& Johnson, C. 2007: 3-4).

Klasifikasi periklanan pun tidak bisa dijelaskan dalam istilah tunggal, jelas, dan menyeluruh yang bisa menggambarkan karakter kompleks periklanan dan fungsi-fungsinya yang majemuk dan saling terkait. Periklanan sering kali diklasifikasi dalam beberapa tipe besar. Yaitu periklanan produk, periklanan eceran, periklanan korporasi, periklanan bisnis ke bisnis, periklanan politik, periklanan direktori, periklanan respon langsung, periklanan pelayanan masyarakat, dan periklanan advokasi [4](Lee, M \& Johnson, C. 2007: 4-10).

Pada sistem ekonomi yang berlandaskan pada pasar, konsumen semakin mengandalkan iklan dan bentuk promosi lainnya untuk mendapatkan informasi yang akan mereka gunakan untuk membuat keputusan apakah akan membeli suatu produk ataukah tidak. Semakin meningkatkan pengeluaran (belanja) iklan dan promosi yang dilakukan perusahaan menjadi bukti bahwa tenaga pemasaran di manapun di dunia mengakui pentingnya kegiatan iklan dan promosi [6](Morissan, 2010:1).

Tujuan dasar iklan sendiri adalah untuk pemberian informasi tentang suatu produk atau layanan jasa dengan cara dan strategi persuasif, agar berita atau pesan dapat dipahami, diterima dan disimpan-diingat, Pemenang Gold, Silver, Dan Bronze Citra Pariwara 2015 serta adanya tindakan tertentu (membeli) yang ditingkatkan dengan cara menarik perhatian konsumen serta menimbulkan asosiasi-asosiasi yang dapat menggugah selera, agar bertindak sesuai keinginan komunikatornya (Anastasi 1989, dikutip dari Widyatama, 2011:30).

\section{Iklan Cetak}

Iklan cetak dalam karakteristiknya sangat menggunakan elemen visual, elemen visual sendiri berguna untuk mampu menarik perhatian dan dapat menyampaikan suatu gagasan atau citra serta dapat berkerja sama secara sinergis dengan judul dan badan iklan sehingga dapat menghasilkan suatu pesan yang efektif. Elemen visual adakalanya menjadi esensi atau inti dari suatu pesan iklan, dengan demikian elemen visual harus mampu menampilkan suatu citra yang kuat dan bermakna [6](Morrisan, 2010:363).

Iklan cetak dalam menyampaikan pesannya juga berhubungan dengan pesan visual, pesan visual yang dibangun dan ada dalam suatu iklan [1](Pete Barry, 2012:146)1, yaitu : pesan tersampaikan dengan lugas (literal) dan pesan tersampaikan dengan kias/ teknik metafora (lateral). Dalam pembuatan iklan cetak pun selain menggunakan pesan secara visual diperlukan penggunaan kata/ kalimat (copy) sebagai penarik perhatian serta peletakan tata letak/ layout yang memberikan kesan artistik dan kreatif terhadap iklan yang dibuat oleh seorang copywriter atau seseorang untuk membuat iklan.

Penggunaan kalimat tersebut adalah headline Umumnya headline berisi kalimat atau kata yang mengandung kesan kuat sehingga menarik minat perhatian khalayak sangat 
Dina Nur Handayani, Ratih Hasanah Sudrajat, Ayub Ilfandy Imran

persuasif, kadang malah profokatif (Widyatama, 2011:101). Kategori jenis headline adalah Curiosity headline, fear headline, split headline, text display headline, cuplikan headline, command headline, headline gambar dan keterangan.

Begitu juga tata letak/ layout, tata letak/ layout diperlukan akan sangat menguntungkan untuk hasil iklan yang bagus dan kreatif [3](Kusrianto, 2007:310). Jenis-jenis tata letak/ layout adalah mondrian layout, multipanel layout, picture window layout, copy heavy layout, frame layout, grid layout, bleed layout, informal balance layout.

\section{Kreatifitas}

Kreatifitas adalah salah satu kata yang mungkin paling sering dan umum digunakan dalam industri periklana. Iklan bahkan kerap disebut dengan kata kreatif saja. Mereka yang terlibat dalam produksi iklan sering disebut dengan tim kreatif, atau orang kreatif. Tanggung jawab tim kreatif adalah mengubah seluruh informasi mengenai produk seperti atribut atau manfaat produk hingga tujuan komunikasi yang ditetapkan menjadi suatu bentuk konsep kreatif yang mampu menyampaikan pesan pemasaran kepada khalayak [7] (Morrisan, 2014:342)

Menurut (Munandar, 1987) yang mengemukakan kreativitas sebagai kemampuan dalam 4P yaitu person, process, press, dan product. Menurut Rhodes, kreativitas harus ditinjau dari segi pribadi (person) yang kreatif, proses yang kreatif, pendorong kreatif dan hasil kreatifitas. (dikutip dari, http://www.galeripustaka.com/). Kreativitas merupakan hal yang berasal dari individu, bagaimana proses berfikir dari tiap
Analisis Isi Visual Iklan Dan Strategi Kreatif Kategori Print Ad Pemenang Gold, Silver, Dan Bronze Citra Pariwara 2015 individu dalam membuat suatu karya menjadi suatu yang kreatif memerlukan tahapn berfikir yang ada dalam dirinya sendiri, dan bagaimana orang tersebut membentuk suatu karya yang baru.

\section{a. Creative Thinking}

Komunikasi dalam diri yang kondusif akan melahirkan pribadi yang kreatif. Dalam hal ini, berpikir kreatif akan menjadikan seseorang menghasilkan suatu karya yang dapat menjembatani keberadaannya dalam kehidupan karena ia dianggap orang lain sebagai penemu dan pencipta. Maka, ia akan banyak berhubungan dengan orang lain dan komunikasi interpersonalnya juga akn membangun dirinya. Berpikir objektif itulah yang akan membuat individu menjadi kuat, berdaya, dan tidak dipermainkan perasaan yang melemahkan (Soyomukti, 2010:114115). Banyak yang beranggapan bahwa komunikasi intra-personal, terutama berfikir (baik yang autistik maupun realistis), akan mendukung kecerdasan kreatif ini (Soyomukti, 2010:115)

\section{Strategi Kreatif}

Pesan berdasarkan tingkat yang diinginkannya adalah pesan yang harus mengatakan sesuatu yang diinginkan atau menarik pada produk tersebut. Pesan berdasarkan tingkat keekslusifannya adalah pesan yang harus mengatakan sesuatu yang ekslusif atau yang membedakannya dari semua merek di dalam kategori produk tersebut [5] (Suyanto, 2004:14).

Pendekatan strategi kreatif mencakup, pendekatan proposisi penjualan unik (Unique selling propotition approach-USP), pendeka- 
tan citra merek, pendekatan pemosisian, pendekatan merek generik, dan pendekatan resonansi [4](Lee, M \& Johnson, C, 2007).

Strategi untuk membuat iklan selain strategi kreatif diperlukan daya tarik pesan apakah yang akan disampaikan kedalam iklan. Daya tarik pesan sendiri berguna sebagai main idea. [5](Suyanto, 2004:123) daya tarik pesan mencakup: daya tarik selebritis, daya tarik humor, daya tarik rasa takut, daya tarik komparatif, daya tarik positif/ rasional, daya tarik emosional, dan daya tarik kombinasi.

Sedangkan untuk format dan gaya eksekusi dalam [7](Morrisan, 2014:352-358) penting dilakukan untuk bagaimana iklan dapat kreatif dan efektif dalam hal menarik perhatian yang melihat iklan tersebut dalam pengeksekusiannya. Hal-hal yang termasuk dalam format dan gaya eksekusi pesan adalah iklan pesan faktual/ penjualan langsung, iklan bukti ilmiah/ teknis, iklan demonstrasi, iklan perbandingan, iklan kesaksian atau testimonial, iklan simbol personalitas, iklan dramatisasi, dan iklan kombinasi.

\section{Metode Penelitian}

Metode penelitian yang dilakukan dalam penelitian ini adalah metode deskriptif kuantitatif, dengan teknik analisis isi. Metode deskriptif kuantitatif sendiri adalah metode yang hanya memberikan gambaran atau deskripsi tentang variabel dari sebuah fenomena yang diteliti. Penelitian deskriptif sendiri hanya memaparkan situasi atau peristiwa, atau mencari atau menjelaskan hubungan, tidak menguji hipotesis atau membuat prediksi. Metode deskriptif dirancang untuk mengumpulkan informasi tentang keadaan-keadaan nyata yang sekarang berlangsung (Ardianto, 2011:49).
Analisis Isi Visual Iklan Dan Strategi Kreatif Kategori Print Ad Pemenang Gold, Silver, Dan Bronze Citra Pariwara 2015

Analisis isi deskriptif adalah analisis isi yang tidak dimaksudkan untuk menguji suatu hipotesis tertentu, atau menguji hubungan antar variabel. Dikutip dalam [2] (Eriyanto, 2011: 47) Analisis semata untuk deskripsi, menggambarkan aspek-aspek dan karakteristik dari suatu pesan. Analisis isi pada dasarnya merupakan suatu cara menyandi (coding) pernyataan atau tulisan agar diperoleh ciri-ciri atau sifatsifat tertentu melalui konstruksi kategori. Pada penelitian ini penyandian dilakukan berdasarkan konstruk kategori yang telah disusun. Isi (content) komunikasi yang menjadi objek penelitian adalah berbentuk isi pesan visual, teknik visual, dan strategi kreatif dari iklan pemenang Citra Pariwara 2015 kategori print ad.

\subsection{Unit Analisis}

Unit analisis adalah penempatan kriteria tertentu yang relevan dengan unit kategori. Selain itu, (Krippendorff, 2007:97 dalam Eriyanto, 2011:59) mendefinisikan unit analisis sebagai apa yang diobservasi, dicatatat dan dianggap sebagai data, memisahkan menurut batas-batasnya dan mengidentifikasi untuk analisis berikutnya.

Kriteria ini nantinya akan menjadi acuan dalam menguraikan isi yang menggambarkan karakteristik teknik visual, isi visual, dan strategi kreatif yang digunakan oleh pemenang penghargaan (gold, silver, bronze) Citra Pariwara 2015 kategori print ad. 
Dina Nur Handayani, Ratih Hasanah Sudrajat, Ayub Ilfandy Imran

Tabel 3.1. Unit Analisis
No Unit Analisis

Jenis Headline

1 (Widyatama:

2011:101)
Tata letak/
Layout
(Kusrianto,
2007:310)

Isi pesan
visual iklan
(Pete Barry,
2012:146) strategi kreatif

4 (Lee, M \& Johnson, C (2007: 177178)

Daya tarik

5 pesan

(Suyanto,

(2004:123)

\section{Kategori}

a. Curiosity Headline

b. Fear Headline

c. Split Headline

d. Text display

Headline

e. Cuplikan Headline

f. Command

Headline

g. Headline gambar dan keterangan

a. Mondrian Layout

b. Multipanel Layout

c. Picture Window Layout

d. Copy Heavy

Layout

e. Frame Layout

f. Grid Layout

g. Bleed Layout

h. Informal Balance Layout

a. Pesan tersampaikan dengan lugas (literal)

b. Pesan tersampaikan dengan kias/ teknik metafora/ (lateral)

a. Pendekatan Proposisi Penjualan Unik (Unique Selling Proposition Approach-USP)

b. Pendekatan Citra Merek

c. Pendekatan Pemosisian

d. Pendekatan Merek Generik

e. Pendekatan Resonansi

a. Daya Tarik Selebritis

b. Daya Tarik Humor

c. Daya Tarik Rasa Takut

d. Daya Tarik Komparatif

e. Daya Tarik Positif/ Rasional

f. Daya Tarik Emosional

g. Daya Tarik Kombinasi
Analisis Isi Visual Iklan Dan Strategi Kreatif Kategori Print Ad Pemenang Gold, Silver, Dan Bronze Citra Pariwara 2015

a. Iklan Pesan Faktual/Penjualan

Langsung

b. Iklan Bukti Ilmiah/

Format dan gaya eksekusi c. Iklan Demonstrasi

6 (Morrisan,

d. Iklan Perbandingan

e. Iklan Kesaksian Atau Testimonial

f. Iklan Simbol Personalitas

g. Iklan Dramatisasi

h. Iklan Kombinasi

Sumber: Olahan Peneliti (2015)

\section{Blaif Keabsahan Data}

Dikutip dari (Ardianto, 2011:187) validitas adalah keabsahan atau akurasi suatu alat ukur, sedangkan reliabilitas adalah dapat dipercayainya alat ukur tersebut. Ketika ingin meneliti suatu masalah menggunakan kuesioner atau angket, angket atau kuesioner tersebut harus diuji validitas dan reliabilitas kepada responden yang setara dengan responden yang menjadi sampel penelitian.

\subsection{Uji Validitas}

Alat ukur harus mempunyai validitas yang tinggi. Validitas berkaitan dengan apakah alat ukur yang dipakai secara tepat mengukur konsep yang ingin diukur. Validitas sangat penting dalam analisis isi. Hal ini karena temuan-temuan dalam analisis isi didasarkan pada alat ukur yang dipakai. Dalam (Eriyanto, 2011:259).

Sedangkan validitas isi berkaitan dengan "Apakah alat ukur telah memasukkan semua dimensi, semua kategori secara lengkap dari konsep yang hendak diukur, sehingga tidak ada yang terlewatkan." (Neuendorf dalam Eriyanto, 2011: 273). Sebuah alat ukur disebut mempunyai validitas isi jika alat ukur menyertakan semua indikator dari konsep, tidak ada yang terlewatkan.

Pada penelitian ini peneliti menggunakan kategorisasi dan meng- 
gunakan alat ukur berupa menghitung berapa jumlah frekuensi teknik visual, isi visual, dan strategi kreatif yang digunakan oleh pemenang penghargaan (gold, silver, bronze) citra pariwara 2015 kategori print ad.

\subsection{Uji Reliabilitas}

Alat ukur selain harus valid juga harus mempunyai realibilitas (keandalan) yang tinggi. Analisis isi haruslah dilakukan secara objektif. Ini berarti tidak boleh ada beda penafsiran antara satu orang coder dan coder yang lain. Dalam analisis isi, alat ukur yang dipakai adalah lembar coding (coding sheet). Kita harus memastikan bahwa lembar coding yang akan dipakai adalah alat ukur yang terpercaya (reliabel). Selalu ada perbedaan antara satu orang dan orang lain ketika menilai suatu iklan. Pada praktiknya, perbedaan interpretasi antara coder pertama, kedua, dan ketiga akan selalu ada. Analisis isi memberi panduan toleransi berapa besar perbedaan yang dapat diterima (Eriyanto, 2011:281).

Formula Holtsi adalah uji realibilitas antarcoder yang pertama kali di kenalkan oleh Ole R. Holsti. realibilitas ditunjukan pada presentase persetujuan berapa besar presentase persamaan antarcoder ketika menilai suatu isi (Eriyanto, 2011:290). Berikut adalah rumus dari formula Holsti:

\section{Reliabilitas Antar- Coder :}

$$
\frac{2 M}{N 1+N 2}
$$

Keterangan :

CR : Coefficient Reliability (reliabilitas antar-coder)

M : Jumlah pernyataan yang disetujui oleh masing masing coderl Jumlah Objek

N1, N2 : Jumlah pernyataan yang
Analisis Isi Visual Iklan Dan Strategi Kreatif Kategori Print Ad Pemenang Gold, Silver, Dan Bronze Citra Pariwara 2015 di beri kode oleh masingmasing coder

Menurut (Eriyanto, 2011:290), reliabilitas bergerak antara 0 sampai 1 , di mana 0 tidak ada satu pun yang disetujui oleh para coder, dan 1 berarti persetujuan sempurna di antara para coder. Makin tinggi angka, makin tinggi pula angka reliabilitas. Dalam formula Holsti, angka reliabilitas minimum yang ditoleransi adalah 0,7 atau $70 \%$. Artinya, kalau hasil penghitungan menunjukan angka reliabilitas diatas 0,7 berarti alat ukur ini benar-benar reliable. Sedangkan, jika dibawah angka 0,7 berarti alat ukur (coding sheet) bukan alat yang reliable.

\subsection{Teknik Analisis Data}

Dikutip dalam (Eriyanto, 2011:202) Dalam analisis isi kuantitatif teknik pengumpulan dan analisis datanya menggunakan prinsip pengukuran (measurement). Lewat pengukuran konsep diturunkan secara operasional dengan diberi angka atau simbol. Setelah semua berita telah di coding langkah selanjutnya adalah melakukan input atau rekap data (Eriyanto, 2011:305). Tahap awal adalah mendeskripsikan temuan. Ini menggunakan statistik yang disebut statistik deskriptif. Dan salah satunya dideskripsikan menggunakan bentuk tabel frekuensi. Pada penelitian kali ini peneliti akan menggunakan tabel frekuensi sebagai penyajian data hasil pengkodean.

Pada penelitian ini peneliti akan memaparkan tiga kategori dengan menggunakan alat ukur berupa menghitung berapa jumlah frekuensi teknik visual, isi visual, dan strategi kreatif yang digunakan oleh pemenang penghargaan (gold, silver, bronze) citra pariwara 2015 kategori print ad. Penelitian ini dibantu oleh tiga orang coder yang diberikan 
Dina Nur Handayani, Ratih Hasanah Sudrajat, Ayub Ilfandy Imran

penjelasan dan pelatihan terlebih dahulu sebelum melakukan pengisian coding sheet.

\section{Hasil Penelitian Dan Pembahasan}

\subsubsection{Hasil Penelitian}

Sebelum melakukan penelitian ini, peneliti menentukan jumlah dan hal yang menarik dari objek yang peneliti pilih. Bagaimana seorang agency periklanan mengeksekusi pesan secara implisit melalui iklan. Tidak mudah menjadi dan mendapatkan piala penghargaan gold, silver, dan bronze. Karya-karya yang mendaftarkan diri tidak luput dari tiga tahap penjurian yaitu, tahap administrasi, tahap EPI (Etika Pariwara Indonesia), dan tahap penjurian. Dan hal ini menjadi menarik bagaimana karyakarya yang lolos seleksi menandakan bahwa iklan-iklan tersebut mempunyai kredibilitas tinggi untuk menjadi pemenang.

Setelah peneliti menentukan jumlah dan objek yang tepat, peneliti mengunduh berkas peranti lunak (software) melalui laman (website) resmi dari Citra Pariwara 2015 (www. citrapariwara.com). Berkas yang peneliti ambil meliputi kategori print ad dengan karya yang memenangkan penghargaan gold, silver, dan bronze.

Setelah itu, peneliti mencari coder yang mempunyai kredibilitas dalam bidang advertising. Peneliti mendapatkan coder yang diinginkan dari sosial media Linked.in. (www. linkedin.com) adalah situs dimana orang-orang profesional menjual dirinya melalui CV (curriculum vitae) untuk tingkat bisnis dan profesional.

Setelah mendapatkan objek dan coder yang sesuai peneliti inginkan dan memenuhi kriteria, peneliti membuat skema coding dan meng-
Analisis Isi Visual Iklan Dan Strategi Kreatif Kategori Print Ad Pemenang Gold, Silver, Dan Bronze Citra Pariwara 2015 kategorisasikan apa saja yang ingin dicapai serta tujuan untuk menyelesaikan rumusan masalah yang peneliti rumuskan.

\subsubsection{Coder Analisis}

Tahapan selanjutnya untuk menghasilkan data adalah menemui coder untuk mengisi coding sheet yang digunakan peneliti untuk memenuhi syarat reliabilitas. Penghitungan coefficient reliability dilakukan dengan cara :

1. Peneliti menentukan siapa yang menjadi pengkoding pertama, lalu pengkoding kedua dan ketiga. Tiap-tiap dominasi frekuensi yang lebih banyak dari tiap aspek kategori akan menjadi alat ukur yang dapat dipercaya.

2 Peneliti menjelaskan batasanbatasan dari unit analisis dan kategorisasi kepada pengkoding pertama, kedua dan ketiga.

3. Pengkoding pertama, kedua dan ketiga melakukan coding dengan coding sheet yang telah peneliti buat lalu mencocokannya dengan unit kategori yang sudah tersedia

4. Hasil pengukuran coding pertama dibandingkan dengan hasil pengukuran pengkoding dua dan tiga agar mendapat hasil penelitian yang reliabel. Kemudian hasil dari coding sheet yang telah dianalisis digunakan untuk menjawab pertanyaan dari rumusan masalah.

Hasil penelitian terdapat enam kategori sebagai tolak ukur untuk mengetahui bagaimana pemenang gold, silver, dan bronze Citra Pariwara 2015 mengeksekusi iklan yang terdiri dari: Jenis headline, tata letak/ layout, isi pesan visual iklan, pendekatan strategi kreatif, daya tarik pesan dan format dan gaya eksekusi pesan. 
Dina Nur Handayani, Ratih Hasanah

Sudrajat, Ayub Ilfandy Imran
Analisis Isi Visual Iklan Dan Strategi Kreatif Kategori Print Ad

Pemenang Gold, Silver, Dan Bronze Citra Pariwara 2015

Tabel 1

Hasil interpretasi dari ketiga coder terhadap tiap kategori

Kategori

Jenis Headline

Tata letak/ Layout

Isi Pesan Visual

Pendekatan Strategi Kreatif

Daya Tarik Pesan

Format dan Gaya Eksekusi Pesan
Hasil

Presentase
Ketiga coder memilih headline gambar dan keterangan sebagai yang paling mendominasi dari 19 buah iklan dari 7 subkategori.Yaitu, curiosity, fear, split, text and display, cuplikan gambar dan keterangan, dan command headline.

Penggunaan frame layout dipilih sebagai sub kategori yang paling banyak dipakai oleh pemenang Sebanyak 11 iklan mewakili dari 8 sub kategori yang tersedia.Sub kategori penggunaan tata letak/layout yang tersedia adalah, Modrian, multipanel, picture tersebut dan menghasilkan window, copy heavy, grid, frame, bleed, informal presentase sebesar 58\%.

balance layout.

Penggunaan isi pesan visual yang paling mendominasi adalah pesan tersampaikan dengan kias, dari 2 sub kategori yang dipakai. Yaitu, pesan tersampaikan dengan lugas (literal) dan pesan tersampaikan dengan kias (lateral).

Penggunaan USP (Unique Selling Proposition) dipilih sebagai sub kategori yang paling banyak dipilih, dari 5 sub kategori yaitu, USP (Unique Selling Proposition), citra merek, pemosisian, merek generik, dan resonansi yang ada.

Coder memilih Penggunaan daya tarik pesan Sebanyak 7 buah iklan kombinasi. Daya tarik pesan mempunyai 7 dipilih untuk mewakili sub kategori yaitu, selebritis, humor, rasa takut, pemakaian sub kategori ini komparatif, positif/ rasional, emosional dan dan menghasilkan presentase kombinasi sebesar $37 \%$.

Penggunaan format dan gaya eksekusi dramatisasi

dipilih sebagai sub kategori yang paling 11 iklan dipilih dan mewakili mendominasi dari 8 sub kategori, 8 sub kategori dari pemakaian sub kategori tersebut adalah penjualan langsung, ilmiah/ teknis, ini dan menghasilkan demonstrasi, perbandingan, kesaksian/ testimonial, presentase sebesar 58\%. simbol personalitas, dramatisasi dan kombinasi.

\section{a. Headline Gambar dan Keterangan}

Headline gambar dan keterangan (Widyatama, 2011:143-184) adalah penggunaan judul yang menggunakan perpanduan antara gambar dan keterangan yang dituliskan di dekatnya (bisa di bawah, samping, atas).

b. Frame Layout

Frame layout adalah suatu tamilan iklan di mana border/bingkai/ frame-nya membentuk suatu naratif (memiliki cerita) [3] (Kusrianto, 2007:277).

\section{c. Isi pesan visual tersampaikan dengan kias}

Pesan tersampaikan dengan kias adalah suatu makna yang implisit dan hanya beberapa orang yang mengerti akan makna sesungguhnya yang akan disampaikan oleh pencipta iklan ${ }^{[1]}$ (Pete Barry, 2012:146).

\section{d. Pendekatan strategi kreatif USP(Unique} Selling Proposition)

Pendekatan proposisi penjualan unik (Unique Selling proposition approachUSP) adalah pengiklan membuat klain atau keunggulan berdasarkan ciri unik produk yang merupakan tersendiri dan bermakna 
Dina Nur Handayani, Ratih Hasanah Sudrajat, Ayub Ilfandy Imran

bagi konsumen ${ }^{[4]}$ (Lee, M \& Johnson, C, 2007).

\section{e. Pendekatan daya tarik pesan kombinasi}

Daya tarik ini perpaduan antara berbagai daya tarik selebritis, humor, rasa takut, komparatif, positif/rasional, dan emosional ${ }^{\text {[5] }}$ (Suyanto, 2004:123).

\section{f. Format dan gaya eksekusi pesan dramatisasi}

Iklan dramatisasi adalah iklan yang menekankan kepada penyampaian cerita pendek (telling a short story) pada akhirnya cerita produk tengah dipromosikan, tampil sebagai bintangnya ${ }^{[7]}$ (Morrisan, 2014:352-358).

\subsection{Pembahasan}

Hasil penelitian ini didapatkan bahwa untuk kategori unit analisis isi visual iklan ketiga coder setuju bahwa analisis isi visual iklan yang dibuat oleh pemenang menggunakan pesan tersampaikan dengan kias/ teknik metafora/ (lateral). Pesan tersampaikan dengan kias/ teknik metafora adalah suatu pesan visual yang biasanya mengungkapkan apa yang dimaksud dan diterjemahkan dalam bentuk eksekusi yang implisit dan hanya orang tertentu yang mengerti akan apa yang dimaksud.

Gambar 4.2.1.

Contoh Unit Analisis Isi Visual

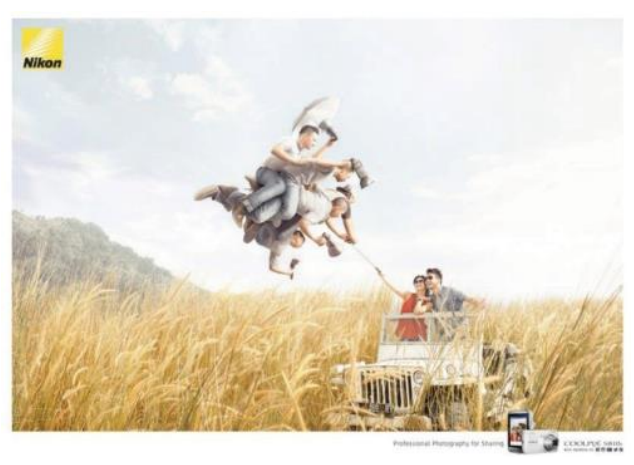

Sumber: www.citrapariwara.org

Sebagai contoh pemenang gold dan silver dalam Citra Pariwara
Analisis Isi Visual Iklan Dan Strategi Kreatif Kategori Print Ad Pemenang Gold, Silver, Dan Bronze Citra Pariwara 2015

2015 berikut. Nikon sebagai produk dari PT. Nikon Indonesia memercayai J. Walter Thompson Jakarta sebagai eksekutor pembuatan iklan cetak sub kategori serial campaign. Dalam pengeksekusiannya J. W. Thompson mengeksekusi Nikon sebagai produk yang dapat dipercaya, dapat menghasilkan hasil yang baik dan nyata dalam menghasilkan gambar fotonya.

Pembahasan dalam unit analisis teknik visual ini terdiri dari Kategori teknik visual memiliki dua sub kategori, yaitu teknik penggunaan jenis headline dan penggunaan tata letak/ layout. Penempatan layout akan sangat berpengaruh terhadap estetika iklan. Ketiga coder setuju bahwa frekuensi yang paling banyak digunakan oleh pemenang Citra Pariwara 2015 kategori print ad adalah penggunaan headline gambar dan keterangan. Dalam (Widyatama, 2011:143-148), headline gambar dan keterangan adalah, judul yang menggunakan perpaduan antara gambar dan keterangan yang dituliskan di dekatnya (bisa di bawah, samping, atas).

Gambar 4.2.2.

Contoh Unit Analisis Teknik Visual (headline)

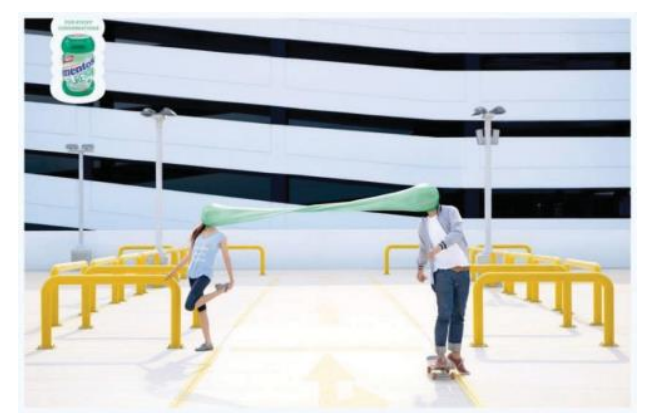

Seperti J. Walter Thompson mengeksekusi penggunaan headline dari serial campaign mentos pure fresh, dengan judul "for sticky conversation" ketiga coder setuju bahwa penggunaan headline menggunakan 
Dina Nur Handayani, Ratih Hasanah

Sudrajat, Ayub Ilfandy Imran

gambar dan keterangan. Hal tersebut dibuktikan oleh pengeksekusiannya yang meletakkan headline sebagai keterangan dan menampilkan foto produk sebagai gambar.

\section{Gambar 4.2.3.}

Contoh Unit Analisis Teknik Visual (tata letak/ layout)

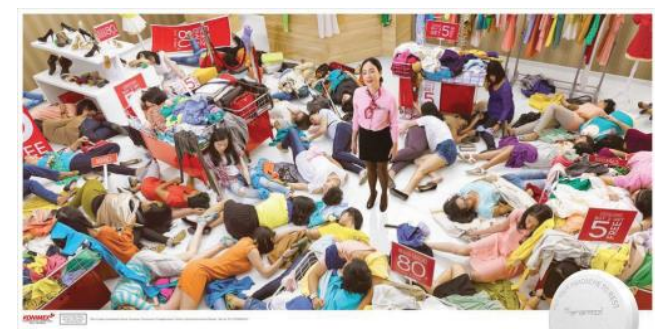

Sedangkan untuk penggunaan tata letak/ layout ketiga coder setuju bahwa pemenang gold, silver, dan bronze Citra Pariwara 2015 kategori print ad menggunakan tata letak bingkai/ frame layout. Seperti contoh salah satu pemenang bronze Citra Pariwara 2015 yang dimenangkan oleh agency PT. Indo Ad dengan produk paramex. Pt-Indo Ad mengeksekusi tata letak/layout-nya menggunakan tata letak frame layout. Ilustrasi gambar dan keterangan сору/ tulisan dibuat seolah sebagai potret dengan bingkai.

Unit analisis strategi kreatif mempunyai tiga sub kategori yaitu, pendekatan strategi kreatif, pendekatan daya tarik pesan, dan format gaya eksekusi pesan. Ketiganya mempunyai andil bagaimana suatu iklan dieksekusi sebagai suatu kesatuan yang menarik dan dari hasil estetikanya sendiri menjadi pembeda dari satu iklan kepada iklan yang lain.

Interpretasi unit analisis pendekatan strategi kreatif ketiga coder setuju bahwa pemenang gold, silver, dan bronze Citra Pariwara 2015 kategori print ad memakai pendekatan proposisi penjualan unik (unique selling proposition approach-USP). Seperti iklan yang memenangi piala
Analisis Isi Visual Iklan Dan Strategi Kreatif Kategori Print Ad Pemenang Gold, Silver, Dan Bronze Citra Pariwara 2015 bronze dengan agency PT. Hakuhodo Indonesia. Agency ini menangani produk tiket dari perusahaan tiket. com, agency ini mengeksekusi iklannya menggunakan pendekatan strategi kreatif USP (unique selling proposition approach).

Gambar 4.2.4.

Contoh Unit Analisis Strategi Kreatif (Pendekatan strategi kreatif)

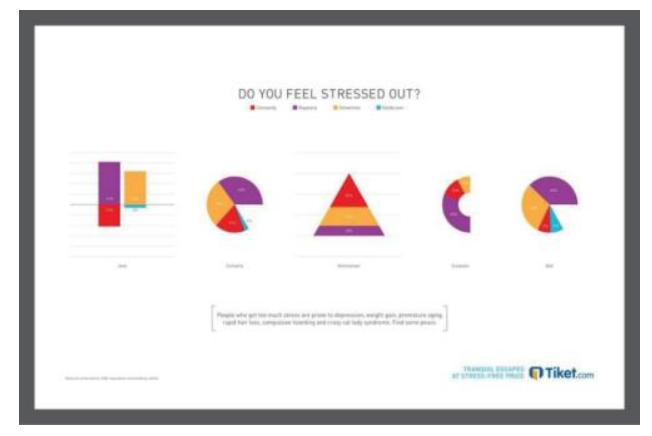

Sumber: www.citrapariwara.org

Pengiklan membuat klaim keunggulan berdasarkan ciri unik produk yang merupakan manfaat tersendiri dan bermakna bagi konsumen. Agency yang membuat iklan ini memunculkan fakta-fakta bahwa "Orang yang mendapatkan stress adalah orang yang gampang terkena depresi, kenaikan berat badan, penuaan dini, kehilangan rambut, sifat penimbunan uang, dan menjadi wanita kucing yang gila, temukan kedamaian" didukung oleh asosiasi produknya yang melayani tiket perjalanan untuk keluar kota yang digambarkan skema tabung dan diagram dengan tiap nama kota yaitu, jawa, sumatra, kalimantan, sulawesi, dan bali membentuk kalimat PEACE.

Unit analisis strategi kreatif untuk pendekatan daya tarik pesan, ketiga coder setuju bahwa frekuensi daya tarik kombinasi lebih mendominasi dari 19 karya yang dibuat oleh pemenang gold, silver, dan bronze Citra Pariwara 2015 kategori print ad. Pemenang silver untuk sub kat- 
Dina Nur Handayani, Ratih Hasanah Sudrajat, Ayub Ilfandy Imran

egori public service advertisement ini dipilih oleh ketiga coder menggunakan pendekatan daya tarik pesan kombinasi yaitu, daya tarik selebritis dan daya tarik emosional. J. Walter Thompson Jakarta sebagai agency yang mengeksekusi produk JDDC, konsultan keselamatan berkendara. Agency ini mengasosiasikan quotes dari Bob Marley "Money can't buy life" dengan pendekatan daya tarik pesan menggunakan selebritis yaitu bob marley. Lalu, pengeksekusiannya ditambahkan dengan daya tarik emosional dengan quotes dari Kevin Febriano, seorang korban kecelakaan mobil pada tahun 2015 dengan quotes terakhirnya "Dude txt me ur addr|" didukung oleh headline yang dibuat oleh JDDC sendiri yaitu "make your last words count don't text and drive" yang mengunggah sisi emosi dari orang yang melihat iklan tersebut.

Gambar 4.2.5.

Contoh Unit Analisis Strategi Kreatif (Pendekatan daya tarik pesan)

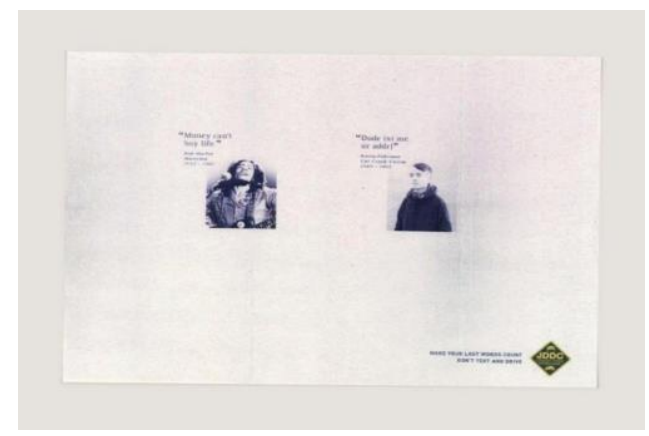

Sumber: www.citrapariwara.org

Sedangkan untuk unit analisis strategi kreatif pendekatan format dan gaya eksekusi dari 19 iklan pemenang gold, silver, dan bronze Citra Pariwara 2015 menggunakan pendekatan format dan gaya eksekusi dramatisasi. Antimo sebagai produk obat anti mabuk dieksekusi dengan kesan dramatis, terlihat dengan pengasosiasian kapal laut yang berjalan lancar di tengah badai di lautan. PT. Hakuhodo sebagai
Analisis Isi Visual Iklan Dan Strategi Kreatif Kategori Print Ad Pemenang Gold, Silver, Dan Bronze Citra Pariwara 2015 agency mendapatkan piala bronze untuk karya ini. Ditambah headline yang mendukung yaitu "No more motion sickness" menjadikan kesan dramatisasi semakin terlihat.

Gambar 4.2.6.

Contoh Unit Analisis Strategi Kreatif

(Pendekatan format dan gaya eksekusi pesan)

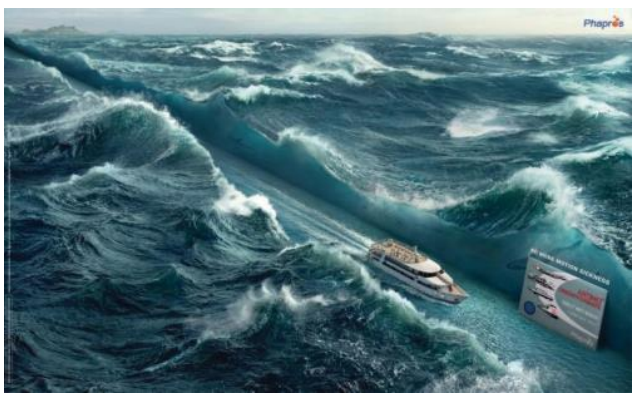

Sumber: www.citrapariwara.org

\section{Kesimpulan dan Saran}

\subsection{Kesimpulan}

Berdasarkan seluruh uraian pada bab sebelumnya, maka dapat ditarik kesimpulan sebagai berikut:

1) Isi pesan visual yang dipakai oleh pemenang gold, silver, dan bronze Citra Pariwara 2015 kategori print ad menggunakan pesan tersampaikan dengan kias/ teknik metafora/ (lateral).

2) Teknik visual memiliki dua sub kategori, yaitu teknik penggunaan jenis headline dan penggunaan tata letak/layout. Teknik visual dalam penggunaan headline yang dipakai oleh 19 karya iklan pemenang gold, silver, dan bronze Citra Pariwara 2015 kategori print ad berdasarkan hasil frekuensi paling dominan adalah menggunakan jenis headline gambar dan keterangan dengan presentase sebesar $32 \%$. Sedangkan, penggunaan tata letak/layout yang digunakan oleh pemenang gold, silver, dan bronze Citra Pariwara 2015 
Dina Nur Handayani, Ratih Hasanah

Sudrajat, Ayub Ilfandy Imran

kategori print ad berdasarkan presentase yang paling besar adalah frame layout, dengan presentase sebesar 58\%.

3) Strategi kreatif mempunyai tiga sub kategori yang terdiri dari, pendekatan strategi kreatif, pendekatan daya tarik pesan, kemudian pendekatan format dan gaya eksekusi pesan. Dari pendekatan strategi kreatif interpretasi dari ketiga coder memilih bahwa pemenang menggunakan pendekatan kreatif USP (Unique Selling Proposition) dengan presentase paling besar 53\%. Berdasarkan strategi kreatif dalam penggunaan pendekatan daya tarik pesan dari interpretasi ketiga coder menunjukan bahwa ketiganya setuju pemenang gold, silver, dan bronze Citra Pariwara 2015 kategori print ad menggunakan pendekatan daya tarik pesan kombinasi dengan presentase sebesar 37\%. Sedangkan untuk strategi kreatif dalam penggunaan format dan gaya eksekusi pesan dari interpretasi ketiga coder menunjukan bahwa ketiganya setuju pemenang gold, silver, dan bronze Citra Pariwara 2015 kategori print ad memakai format dan gaya eksekusi dramatisasi dengan presentase yang paling dominan sebesar $58 \%$.

\section{Saran}

1) Hasil interpretasi dari ketiga coder dapat menjadi pengetahuan bagaimana interpretasi dari tiap subkategori dapat menggambarkan secara keseluruhan objek yang nantinya akan menjadi acuan untuk membuat iklan yang lebih baik lagi.

2) Hasil penelitian ini dapat mem-
Analisis Isi Visual Iklan Dan Strategi Kreatif Kategori Print Ad Pemenang Gold, Silver, Dan Bronze Citra Pariwara 2015 perkaya dan melengkapi pustaka bidang periklanan dan pemasaran sebagai sarana peningkatan apresiasi terhadap ajang Citra Pariwara dalam peningkatan ide kreatif untuk membuat iklan dari tahun ke tahun.

3) Banyaknya iklan-iklan peraih penghargaan ataupun iklan yang mendaftarkan dalam festival Citra Pariwara 2015 dapat menjadi sumber motivasi, semangat, dan menggali kreatifitas lebih jauh, dan banyak lagi untuk praktisi periklanan maupun masyarakat untuk menyalurkan suatu sumber kreatifitas.

\section{Daftar Pustaka}

${ }^{[1]}$ Barry, Pete. 2012. Advertising Cocept Book Second Edition. China : Toppan Printing

${ }^{[2]}$ Erianto. 2011. Analisis Isi Pengantar Metodologi Untuk Penelitian Ilmu Котиnikasi

Dan Ilmu-Ilmu Sosial Lainnya. Jakarta : Kencana

${ }^{[3]}$ Kusrianto, Adi. 2007. Pengantar Desain Komunikasi Visual. Yogyakarta : ANDI

${ }^{[4]}$ Lee Monlee \& Johnson Carla. 2007. PrinsipPrinsip Pokok Periklanan Dalam Perspektif Global Edisi Ke-2. Jakarta : Kencana

${ }^{[5]}$ M, Suyanto. 2004. Aplikasi Desain Grafis Untuk Periklanan Di Lengkapi Sampel Iklan Terbaik Di Dunia. Yogyakarta : ANDI

${ }^{[6]}$ Morrisan, MA. 2010. Periklanan Komunikasi Pemasaran Terpadu Edisi Pertama Cetakan Ke-1. Jakarta : Kencana

${ }^{[7]}$ Morrisan, MA. 2014. Periklanan Komunikasi Pemasaran Terpadu Edisi Pertama Cetakan Ke-2. Jakarta : Kencana

${ }^{[8]}$ Nazoeaggi, Tano. 2011. Analisis isi pesan kreatif iklan media cetak peraih medali 
Dina Nur Handayani, Ratih Hasanah Sudrajat, Ayub Ilfandy Imran

emas penghargaan bulanan dalam forum http://www.adsoftheworld.com Periode oktober 2008 hingga maret 2011. Skripsi S1 Ilmu Komunikasi Universitas Pembangunan Nasional "Veteran" Yogyakarta.

${ }^{[9]}$ Utami, Putri Diyah dan Kusumawati, Diah. 2014. Strategi dan eksekusi kreatif iklaniklan peraih penghargaan citra pariwara 2013 (studi analisis isistrategi dan eksekusi kreatif iklan-iklan peraih penghargaan citra pariwara 2013 kategori print dan film). (https://digilib.uns.ac.id).
Analisis Isi Visual Iklan Dan Strategi Kreatif Kategori Print Ad Pemenang Gold, Silver, Dan Bronze Citra Pariwara 2015 